\title{
TIEMPO E HISTORIA EN EL CINE CUBANO DE LOS AÑOS 1960 Y $1970^{1},{ }^{2}$
}

\author{
Time and History in Cuban cinema \\ of sixties and seventies
}

Ignacio Del Valle Dávila*

\begin{abstract}
RESUMEN
La ley de fundación del Instituto Cubano del Arte y la Industria Cinematográficos (ICAIC) de 1959, estableció que la historia cubana sería uno de los principales temas del cine de la isla. Sin embargo, solo a partir de 1968, con motivo del centenario de la Guerra de los diez años (1868 - 1878), se privilegió la producción de un cine histórico que abordó el proceso de independencia. Este ciclo formó parte de la política cultural desarrollada durante la llamada "Ofensiva revolucionaria", que se caracterizó por un mayor control de la libertad creativa de los artistas nacionales. En este artículo, propongo un análisis de los largometrajes Lucía (Humberto Solás, 1968) y La primera carga al machete (Manuel Octavio Gómez, 1969), a través del cual estudiaré cómo el ICAIC asoció las guerras de independencia con la revolución cubana, dentro de un ciclo conocido como los "Cien años de lucha" por la liberación. En dicho ciclo el régimen castrista fue visto como una culminación del proceso de independencia.
\end{abstract}

Palabras clave: cien años de lucha; Cuba; cine.

\begin{abstract}
The law of foundation of the Cuban Institute of the Art and the Industry Cinematographic (ICAIC) of 1959 established that the Cuban history

"Posdoctorando en Historia, USP. elvalledeignacio@gmail.com

1 Este trabajo forma parte de una investigación de posdoctorado sobre la representación de la independencia en Brasil, Argentina y Cuba durante los años 1960/1970, titulada: "Representações cinematográficas da independência sob regimes autoritários na América Latina". El proyecto cuenta con financiación de la Fundação de Amparo à Pesquisa do Estado de São Paulo (FAPESP).

2 Algunos aspectos del presente artículo fueron abordados por el autor, en forma sucinta, en el texto "La primera carga al machete (1969): El cine cubano y los Cien años de lucha", presentado en el IV Congreso Asaeca, Rosario, 13-15 de marzo de 2014.
\end{abstract}


would be one of the principal topics of the cinema of Cuba. However, only in 1968, on the occasion of the centenary of the War of ten years $(1868$ - 1878), there was favoured the production of a cinema about Independence. This cycle was part of the cultural politics developed during the so called "Revolutionary Offensive", which was characterized by a major control of the creative freedom of artists. In this article, I propose an analysis of the films Lucía (Humberto Solás, 1968) and La primera carga al machete (Manuel Octavio Gómez, 1969). This analysis will allow me to study how the ICAIC associated the wars of independence with the Cuban revolution, in a cycle known as the "One Hundred years of struggle" for liberation. In this cycle the Cuban regime was judged as the moment of culmination of the process of independence.

Keywords: one hundred years of struggle; Cuba; cinema.

Lucía (Humberto Solás, 1968) y La primera carga al machete (Manuel Octavio Gómez, 1969) son los dos filmes históricos más representativos de la producción cinematográfica cubana de los años 1960/1970. En estas páginas los insertaré dentro del contexto de producción que le dio origen, poniendo énfasis en el análisis de la política cultural de la revolución cubana a finales de los años 1960. Por otro lado, buscaré establecer las estrategias narrativas y estéticas que Humberto Solás y Manuel Octavio Gómez desarrollaron en sus filmes y que les permitieron satisfacer los lineamientos de esa política oficial, sin renunciar a sus propias inquietudes creativas. Tras diez años de existencia, las producciones del Instituto Cubano del Arte e Industria Cinematográficos (ICAIC), alcanzan con ambos filmes uno de sus puntos más altos de desarrollo formal. Paradójicamente, ello se da en momentos en que la política cultural oficial empezaba a dar signos de una mudanza autoritaria y antiintelectual, que tuvo consecuencias perjudiciales para la libertad creativa.

\section{La política cultural en la "Ofensiva revolucionaria"}

Hacia 1968 la Revolución había dejado atrás la efervescencia de sus primeros años y comenzaba a manifestar, tanto en el plano interno como en el internacional, algunos síntomas de crisis. La muerte de Che 
Guevara, en octubre de 1967, significó un serio revés para la estrategia del foco revolucionario animada desde La Habana, en el marco de una política de solidaridad combativa tercermundista. A su vez, la isla enfrentaba el embargo norteamericano y los sabotajes contrarrevolucionarios, así como crecientes problemas de abastecimiento de petróleo y una campaña de industrialización que se saldó con resultados negativos. Frente a la nueva situación, el 13 de marzo de 1968 Fidel Castro proclamó la "Ofensiva revolucionaria”, que significó masivas nacionalizaciones de servicios y pequeños negocios, nuevas movilizaciones generalizadas de la ciudadanía para las labores agrícola y el trabajo voluntario como estrategia para el cumplimiento de metas productivas. El discurso oficial promovió la ofensiva como un sacrificio colectivo -inspirado en la ética voluntarista del "hombre nuevo"- que contribuiría al desarrollo de la revolución ${ }^{3}$. En la práctica, el gobierno hizo de la exportación de azúcar al bloque soviético su principal actividad económica. En los años sucesivos, los planes de cooperación económica entre los países del Este y Cuba traerían como resultado una mayor dependencia respecto de la URSS, que tendría consecuencias políticas y culturales caracterizadas por un endurecimiento del régimen ${ }^{4}$. Una de las primeras y más significativas señales de esa mudanza se llevó a cabo el 23 de agosto de 1968 con el apoyo público de Castro -hasta entonces símbolo de un nuevo modelo de revolución- a la intervención soviética en Praga. La nueva postura del régimen, suscitó la crítica y el progresivo distanciamiento de parte de la intelectualidad latinoamericana y europea, hasta entonces defensora de la Revolución Cubana.

En el contexto de la "Ofensiva revolucionaria" se produjo un mayor control de los intelectuales, de los que se exigió un posicionamiento militante explícito -cuyas últimas consecuencias eran morir en la lucha armada, según el ejemplo de Che Guevara- y una producción artística que estuviese volcada a la educación de un público popular y que, de esta manera, sirviese para el desarrollo y fortalecimiento de la Revolución. En diversas revistas culturales y en numerosas declaraciones públicas se repiten estas ideas, acompañadas de una negación explícita de toda valoración del

3 VILLAÇA, Mariana Martins. Cinema cubano: revolução e política cultural. São Paulo: Alameda, 2010. p. 217-218.

4 MISKULIN, Sílvia Cezar. Os intelectuais cubanos e a política cultural da Revolução (1961-1975). São Paulo: Alameda, 2009. p. 235. 
trabajo intelectual por sobre el manual, pues la sociedad comunista llevaría a que desapareciese toda división entre ambas ${ }^{5}$. $\mathrm{Al}$ respecto, cabe destacar cómo el célebre ensayo de Julio García-Espinosa Por un cine imperfecto (1969) adaptó este discurso al plano cinematográfico al vaticinar la futura desaparición del cine, y en general del arte, en el todo social, cuando la creación cinematográfica estuviese al alcance del pueblo, en una sociedad sin clases ni división del trabajo ${ }^{6}$.

Las propias esferas intelectuales cubanas y latinoamericanas desarrollaron una actitud de desconfianza frente a la noción de "intelectual", la que fue acusada de elitista y burguesa. Según Claudia Gilman, se hacía explícito un abierto antintelectualismo, en el que los actores culturales se subordinaban a la dirigencia política:

\begin{abstract}
"Revolucionario" en este sentido, hace referencia solamente al intelectual que asume como necesaria su colocación subordinada respecto del Estado y sus instituciones. Puesto que ya existía una vanguardia (el gobierno revolucionario) y que ésta se definía en términos excluyentes de liderazgo político (que incluía la difusión y creación de normas estéticas para los productos del arte), la promoción de nuevos grupos vanguardistas resultaba no solamente innecesaria sino incómoda, ya que su sola existencia tendía a cuestionar las políticas estatales en práctica? ${ }^{7}$
\end{abstract}

Las obras artísticas que reflejaban cierta posición crítica, a pesar de que sus autores se autoproclamasen como seguidores del proceso cubano, fueron frecuentemente tildadas de reaccionarias y contrarrevolucionarias. A la censura más o menos evidente de algunas creaciones, se sumó una actitud de mayor contención, cuando no de autocensura, de parte de los propios artistas y de los equipos de trabajo en los que estaban insertos como comités de redacción, instituciones culturales, grupos de creación, etc. El campo cultural y artístico fue sacudido por polémicas públicas y acusaciones entrecruzadas que llevaron a la purga, al ostracismo e incluso

5 Ibidem, p. 186-187.

6 Para un análisis del ensayo de García Espinosa ver: DEL VALLE DÁVILA, Ignacio. Le "Nouveau cinéma latino-américain": un projet de développement cinématographique sous-continental. Tese (Doutorado) - Universidade Toulouse 2 - Le Mirail, 2012. p. 385-433.

7 GILMAN, Claudia. Entre la pluma y el fusil: debates y dilemas del escritor revolucionario en América Latina. 2. ed. Buenos Aires: Siglo Veintiuno Editores, 2012. p. 225. 
al encarcelamiento de algunos autores ${ }^{8}$. El endurecimiento de la política cultural cubana, a fines de los años 1960, anticipaba ya las restricciones a la libertad de creación que impondría, a partir de abril de 1971, el Primer Congreso Nacional de Educación y Cultura, como se verá más adelante.

El sacrificio colectivo y voluntarista promovido por la "Ofensiva revolucionaria" y el mayor control intelectual fueron de la mano con una interpretación oficial de la historia cubana. Las guerras de independencia del siglo XIX y la Revolución de 1959 fueron descritas como distintas etapas de una misma lucha por la liberación nacional, en las que se incluía también la insurrección contra la dictadura de Gerardo Machado en los años 1930 y el asalto al cuartel Moncada en 1953.

Tal reinterpretación de la historia alcanzó una notable publicidad a partir de 1968, con motivo del centenario del inicio de la Guerra de los diez años (1868-1978). La efeméride donó la ocasión para exaltar a través de artículos de prensa, declaraciones públicas y filmes los vínculos entre pasado y presente, en un ciclo que sería conocido como los "Cien años de lucha”. En su discurso del 10 de octubre de 1968, en la Demajagua, Fidel Castro estableció oficialmente esta interpretación de la historia nacional al indicar que la declaración de independencia de 1868 había dado inicio a un proceso revolucionario que se extendía hasta el presente:

Nuestra Revolución, con su estilo, con sus características esenciales, tiene raíces muy profundas en la historia de nuestra patria. Por eso decíamos, y por eso es necesario que lo comprendamos con claridad todos los revolucionarios, que nuestra Revolución es una Revolución, y que esa Revolución comenzó el 10 de Octubre de 1868 (APLAUSOS).

8 El ejemplo más conocido es el del poeta Heberto Padilla, cuya prisión y posterior autocrítica, en 1971, sería duramente atacada por la intelectualidad latinoamericana y europea, que acusó al régimen de caer en prácticas propias del estalinismo. En el campo cinematográfico, cabría mencionarse al documentalista Nicolás Guillén Landrián -sobrino del poeta Nicolás Guillén- cuyos proyectos fueron duramente cuestionados por la dirección del ICAIC, al punto de ser cancelados, ver su estreno postergado o su exhibición en salas reducida a escasas semanas. Guillén Landrián fue expulsado del ICAIC en 1972 y pasó algunos periodos en la cárcel o en centros psiquiátricos antes de exiliarse en EE.UU. Para un estudio del caso Padilla ver: GILMAN, Claudia. Op. cit., p. 233-263; MISKULIN, Sílvia Cezar. Op. cit., p. 208220. Para un estudio de Guillén Landrián ver: VILLAÇA, Mariana Martins. Op. cit., p. 244-250; ZAYAS, Manuel. Nicolás Guillén Landrián: Muerte y resurrección. Cinémas d'Amérique Latine, Toulouse, n. 18, p. 121-134, 2010.

9 CASTRO, Fidel. Discurso pronunciado por el comandante Fidel Castro Ruz, primer secretario del Comité Central del Partido Comunista de Cuba y Primer Ministro del Gobierno Revolucio- 
Esta visión de la historia permitía establecer un nexo de continuidad entre las luchas de los rebeldes mambises y los esfuerzos de los voluntarios en las zafras. Ambos eran entendidos como "sacrificios" revolucionarios. Ello le otorgaba una evidente heroicidad a las labores agrícolas, al tiempo que las convertía en un imperativo para la nación. Así queda de manifiesto en el mismo discurso de Castro: "Y en esa tierra que se regó tantas veces con sangre de patriotas, se riega hoy el sudor honesto de un pueblo [...]"10. Por último, el énfasis otorgado a esta reinterpretación de la historia cubana, permitía al régimen encauzar la actividad artística e intelectual orientándola hacia el elogio y la mitificación del pasado nacional. Al respecto, en el mismo discurso, Castro lanza una crítica abierta al establishment cultural, del que exige un mayor interés por este tipo de temas, que debían ser abordados con finalidades didácticas:

No sé cómo es posible que habiendo tareas tan importantes, tan urgentes como la necesidad de la investigación en la historia de este país, en las raíces de este país, sin embargo, son tan pocos los que se han dedicado a esas tareas. Y antes prefieren dedicar sus talentos a otros problemas, muchos de ellos buscando éxitos baratos mediante lectura efectista, cuando tienen tan increíble caudal, tan increíble tesoro, tan increíble riqueza para ahondar primero que nada y para conocer primero que nada las raíces de este país. Nos interesa más que corrientes que por snobismo puro se trata de introducir en nuestra cultura, la tarea seria, la tarea necesaria, la tarea imprescindible, la tarea justa de ahondar y de profundizar en las raíces de este país ${ }^{11}$.

A finales de 1967 en el Seminario Preparatorio del Congreso Cultural de la Habana ${ }^{12}$, una comisión dirigida por Alfredo Guevara, director del ICAIC, recordaba que en 1968 se conmemoraban los cien años de lucha

nario, en el resumen de la velada conmemorativa de los Cien Años de Lucha, efectuada en la Demajagua, monumento nacional, Manzanillo, Oriente, el 10 de octubre de 1968. Disponible en: <http://www.cuba.cu/ gobierno/discursos/1968/esp/f101068e.html>. Última visita: 27/01/2014.

10 Idem.

11 Idem

12 En el seminario, realizado entre el 25 de octubre y el 2 de noviembre de 1967, se consensuaron las posturas que defenderían los intelectuales cubanos en el Congreso Cultural de la Habana (4 - 12 de enero de 1968). VILLAÇA, Mariana Martins. Op. cit., p. 209. 
por la independencia. El texto fue publicado en la revista Cine Cubano n. $45-46,1968^{13}$. En este sentido, el discurso de Castro no inicia esta historia oficial, que ya se venía gestando, pero sí la consolida.

Aunque la ley de creación del ICAIC de 1959 ya establecía en sus consideraciones preliminares que la historia cubana sería uno de los principales temas del cine nacional, solo a partir del ciclo de los "Cien años de lucha" las guerras de independencia ganaron un lugar central dentro de la producción. Entre 1968 y 1971 se realizaron cuatro largometrajes de ficción que abordaban el proceso de emancipación: Lucía (Humberto Solás, 1968), La odisea del general José (Jorge Fraga, 1968), La primera carga al machete (Manuel Octavio Gómez, 1969) y Páginas del diario de José Martí (José Massip, 1971). A ellos se suman documentales, cortometrajes y mediometrajes como Hombres de mal tiempo (Alejandro Saderman, 1968), El llamado de la hora de (Manuel Herrera, 1969) y Médicos mambises (Santiago Villafuerte, 1969), entre otros.

Los filmes del ciclo de los "Cien años de lucha", adhieren a la historia oficial del régimen a través de distintas estrategias audiovisuales: se trata de paralelos, comparaciones y analogías, tanto explícitos como implícitos, entre la independencia y sus héroes y la revolución de 1959 y sus líderes. El ICAIC elaboró discursos que conferían una legitimidad histórica a la revolución al interpretar el pasado nacional a partir de la coyuntura presente. Pasado y presente se interrelacionaron en un juego de espejos en el que las palabras y actos de Fidel Castro encontraban su reflejo en las palabras y actos de Martí (como se sugiere en Páginas del diario de José Marti); los hermanos Castro tenían su equivalente en los hermanos Maceo (La odisea del general José), y el argentino Che Guevara encontraba su antecedente en el dominicano Máximo Gómez (La primera carga al machete).

En el cine histórico del periodo, el presente actualizó las luchas del pasado a la vez que encontró su confirmación y legitimación en el ejemplo de los próceres nacionales. Como establece Juan Navarro: "De acuerdo con esta visión mítica, el pasado no tiene importancia como tal, sino como anuncio y legitimación del presente" ${ }^{\prime 14}$. Se asiste así a una mitificación de la

13 Ibidem, p. 210.

14 JUAN-NAVARRO, Santiago. ¿Cien años de lucha por la liberación?: las guerras de la Independencia en el cine de ficción del ICAIC. En: BERTHIER, Nancy (Éd.). Cine y revolución cubana: luces y sombras. Archivos de la Filmoteca, n. 59, Valencia, p. 160, junio de 2008, p. 160. 
independencia y de la Revolución, con la subsecuente evacuación de toda posibilidad crítica respecto de ambas. Si bien, los episodios y personajes del presente parecen ser un retorno a los mitos fundacionales del pasado, la concepción del tiempo que proponen los "Cien años de lucha" no es de carácter regresivo sino que escatológico: la historia nacional es la historia del camino hacia la "liberación"15. La lógica que guía los "Cien años de lucha", hace de la "liberación" una "Edad Mítica" situada al final de la Historia, tal y como la entiende Jacques Le Goff:

Para dominar o tempo e a história e satisfazer as próprias aspirações de felicidade e justiça ou os temores face do desenrolar ilusório ou inquietante dos acontecimentos, as sociedades humanas imaginaram a existência, no passado e no futuro, de épocas excepcionalmente felizes ou catastróficas e, por vezes, inseriram essas épocas originais ou derradeiras numa série de idades, segundo uma certa ordem ${ }^{16}$.

El esfuerzo colectivo al que llama la revolución cubana se inserta dentro de una lógica que entiende el tiempo como una progresión hacia una época futura "excepcionalmente feliz", como diría Le Goff. La concepción de la historia promovida por los largometrajes de los "Cien años de lucha" busca potenciar dicho discurso, bien representando el pasado dentro de una lógica evolutiva (fases históricas), o bien mediante una comparación de los sacrificios del pasado con los del presente, que atribuye a ambos la misma finalidad revolucionaria.

\section{Las tres Lucía}

Lucía (Humberto Solás, 1968) es un largometraje episódico compuesto por tres historias ambientadas en momentos clave de los "Cien años

15 Esta visión es coherente con la noción marxista de que una sociedad sin clases será el resultado final de la historia.

16 LE GOFF, Jacques. História e memória. Campinas: Editora da Unicamp, 2013. p. 263. 
de lucha": la segunda guerra de independencia (1895), las luchas contra Machado (1932) y los años 1960. Las tres historias están protagonizadas por una mujer de nombre Lucía y, en ellas, el elemento melodramático -expresado como una relación amorosa tortuosa e infeliz, marcada por la traición o el desengaño- se entrelaza con el contexto histórico de formación de la nación. Cada uno de los tres momentos es representado con un estilo distinto. En el primero, Lucía es una mujer madura de clase alta que se ve engañada por un espía español del que está enamorada y al que revela el escondite de los rebeldes cubanos. El capítulo se caracteriza por su expresividad audiovisual barroca y la sobredimensión de los aspectos emocionales, lo que según Santiago Juan Navarro lo emparenta con el folletín decimonónico ${ }^{17}$. En el segundo de ellos, el favorito de Solás, se opta por un realismo de corte dramático, para dar cuenta, a través de otra Lucía, de los límites de las revueltas contra Machado y la paulatina traición de sus dirigentes. El tercero, ambientado en la campaña de alfabetización, dialoga con la comedia popular al mostrar a una Lucía guajira que se bate contra su marido para aprender a leer y para participar en el trabajo colectivo en los campos. A través de las tres protagonistas, el filme muestra la progresiva toma de conciencia revolucionaria de la sociedad cubana a lo largo de unos setenta años de historia.

Los tres capítulos de Lucía, lo convierten en filme estéticamente ecléctico, que se propone englobar con un gesto ampuloso el pasado reciente de la isla. Esto último lo emparenta con la tradición del cine histórico desde Griffith. Como explica Antoine De Baeque, la grandilocuencia ha sido, la mayoría de las veces, una característica fundamental de ese cine, que mediante la construcción de grandes decorados, vestuarios fastuosos y multitud de extras, ha creado relatos cargados de exotismo, al punto de que "filmar la historia consistía para el cine en rivalizar en ambición épica con esta"18.

Las similitudes entre Intolerancia (D.W. Griffith, 1916) y Lucia son lo suficientemente profundas como para que me parezca posible proponer que el filme de Solás tomó como modelo al primero. Ambos presentan historias ambientadas en distintos momentos del pasado y del presente en el que fueron filmadas. En el filme se Griffith se entrecruzan la caída de Babilonia, la Matanza de San Bartolomé, una historia obrera de comienzos 
del siglo XX y la Pasión de Cristo. En el de Solás, las tres historias que hemos evocado. Ello hace que la duración de ambos sea bastante prolongada: en torno a 160 minutos, en el caso del filme cubano y, dependiendo de la versión, alrededor de tres horas o tres horas y media, en el caso del estadounidense. A su vez, en los dos filmes se presentan tres historias donde los personajes femeninos tienen un rol preponderante y se constituyen en motores de la acción; es el caso de las tres Lucía de Solás y de la Chica de la Montaña, Ojos Castaños y La Encantadora, de Griffith. Es más, algunos rasgos de los personajes femeninos de Intolerancia se pueden encontrar, también, en las mujeres creadas por Solás: la pasión alocada y violenta con la que se muestra en un comienzo a la Chica de la Montaña, y su rebelión contra la autoridad masculina, están presentes también en la última Lucía. El retrato de ambas mujeres, que provienen de medios desfavorecidos, tiene toques de comedia, si bien en el filme de Griffith se terminé por dar paso a un drama épico que se salda con la muerte de la heroína. Aunque en menor medida, también es posible establecer similitudes entre la acomodada Sra. Jenkins que es víctima de la desesperación al descubrir que ha perdido su juventud y la también acomodada Lucía, una mujer que frisa los cuarenta y está angustiada por no encontrar marido. La aflicción de ambas frente al tiempo que se escurre entre sus dedos abre las puertas a la desgracia.

Ahora bien, las tres historias del filme de Solás están enmarcadas en un contexto nacional y abarcan unas siete décadas de historia cubana, mientras que Intolerancia rompe los límites nacionales y entrelaza historias separadas por varios siglos (cuando no milenios). Cómo he mencionado, a las historias donde las mujeres tienen un papel principal, Griffith añade una cuarta, en la que se describen algunos milagros de Cristo y su Pasión en la cruz. Esa cuarta historia da un sentido ulterior a las otras tres. La intolerancia que describe Griffith no puede ser superada ni en la Babilonia pagana, ni en las fratricidas luchas de religión de la Francia de Carlos IX; sin embargo, en el presente del filme, la conversión y la fe cristiana salvan de la horca a un inocente injustamente condenado. Esa misma fe es propuesta, a modo de coda, como una forma de superar las diferencias políticas en momentos en que Europa se desangra, inmersa en la Gran Guerra. En cambio, en Lucía la fe cristiana no es propuesta como una solución. Por el contrario, el filme describe por medio de sus tres protagonistas, el camino de una nación hacia su liberación, una liberación entendida desde una concepción materialista, que niega tanto el pacifismo como la "alienación" religiosa. 
La estructura de Lucía sigue una progresión cronológica -comienza en 1895, sigue en 1932 y culmina en los años 1960-, mientras que en el filme de Griffith los cuatro momentos históricos se alternan y entrecruzan, confluyendo al final. La decisión de Solás, de decantarse por una estructura lineal, mucho más simple, es coherente con su objetivo de mostrar la historia cubana como la evolución hacia la liberación que he descrito más arriba. Así, cada momento histórico supera al tiempo anterior y contiene las enseñanzas heredadas del pasado, como si fueran una suerte de memoria inmaterial. Hay también un desplazamiento social de los protagonistas. Los personajes de la primera historia pertenecen a la aristocracia, los de la segunda a la clase media y los de la tercera son campesinos guajiros. Los antiguos oprimidos terminan, pues, siendo los motores de la historia.

En el filme se presenta una "feminización" de la nación a través de las tres protagonistas, que sirven como alegorías del destino patrio. Esta feminización tiene como antecedente el filme soviético-cubano Soy Cuba (Mijaíl Kalatozov, 1964), donde una narradora femenina se concebía y presentaba al público como voz, conciencia y memoria de la isla. Con todo, pueden encontrarse en la historia del arte innumerables ejemplos de personificación y feminización de la nación a través de alegorías, siendo la Marianne francesa el caso más conocido. Por otro lado, es interesante recordar que los vínculos entre Soy Cuba y Lucía no se limitan al aspecto descrito, sino que también a elementos estéticos, principalmente la fotografía a cargo de Serguéi Urusevski que ejerció una potente influencia sobre el director de fotografía de Lucía, Jorge Herrera, como queda de manifiesto en el expresionismo visual y el alto contraste de las imágenes de la primera parte del filme.

El discurso de los "Cien años de lucha" está claramente presente en Lucía: la lucha de las tres mujeres está ligada al destino de su nación y, en el camino a la liberación que las tres recorren, con mayor o menor fortuna, cada una de ellas tiene un grado de conciencia social mayor a la anterior. Ahora bien, el filme no termina con una celebración de la revolución de 1959, como momento final de la liberación. Como advierte Paranaguá ${ }^{19}$, Solás no concluye con un episodio épico ambientado en la Sierra Maestra -a la que ya se había acercado con su mediometraje Manuela (1966). Decantarse por

19 PARANAGUÁ, Paulo Antonio. Umberto Solás entre Oshum et Shangô. En: (Dir). Le cinéma cubain. Paris: Centre Pompidou, 1990. p. 143. 
esa opción habría permitido clausurar el círculo de luchas abierto con la independencia, es decir, convertir los "Cien años de lucha" en un proceso ya cerrado que termina con el triunfo de Castro. Solás, por el contrario, optó por ambientar su tercera historia después de la revolución y, además, dejarla inconclusa. No sabemos si Lucía conseguirá liberarse del machismo de su esposo, aunque podemos suponerlo. Sea como sea, se da entender que su lucha prosigue más allá de lo que el filme muestra.

La figura del alfabetizador del tercer episodio parece indicar que la historia está ambientada en la masiva campaña de alfabetización realizada durante el Año de la Educación (1961); sin embargo, el filme no dice nada al respecto. Por el contrario, se limita a indicar, con estudiada imprecisión, que la historia transcurre en "196...", lo que refuerza la sensación de inacabamiento y contemporaneidad. Esta estrategia es plenamente pertinente con los fines de la "Ofensiva revolucionaria", pues indica que los "Cien años de lucha" no han terminado y que el trabajo debe continuar.

En este sentido, el tercer episodio del filme ofrece algunas secuencias altamente didácticas, que pueden interpretarse como una propaganda a favor de las labores colectivas en las zafras. El machismo del protagonista del último capítulo es condenado tanto porque impide a Lucía aprender a leer y escribir, como porque no la deja trabajar junto al resto de la comunidad. Dos actitudes que atentan contra los fines de la revolución. El trabajo colectivo, en cambio, es representado como un deber al que la comunidad le da la bienvenida alegremente. En el camión que lleva a las guajiras a las plantaciones estas ríen, aplauden y hacen bromas. Cuando Lucía les comenta que su novio no la dejará continuar acudiendo a los campos después del matrimonio, el grupo de mujeres protestan ruidosamente: “¿Qué trabaje! ¡Qué Trabaje!”.

Acto seguido, las escenas de las labores colectivas son musicalizadas con la canción Guajira Guantanamera, pero la letra tradicional ha sido substituida por otra que hace hincapié en las obligaciones de los campesinos:

El campo, rico caudal de innumerables grandezas, / El campo, rico caudal de innumerables grandezas, / Y de incontables bellezas, / De reposo espiritual, / Hombre y mujer por igual / Estamos en el deber de atender / Y extraer sus productos como oficio / Y obtener el beneficio / Que de él queramos tener. / Él nos regala seguro sus riquezas de aire y sol / Además del lindo arrebol / De un amor sublime y puro. 
Esta representación del trabajo popular es diametralmente distinta a la de otros filmes cubanos ambientados en la Cuba prerrevolucionaria. Así, por ejemplo, el héroe de Las Aventuras de Juan Quin Quin (Julio García Espinosa, 1967) está al borde de ser triturado por una máquina que procesa caña de azúcar en un complejo industrial en manos de un capitalista. Si en ese filme el trabajo es visto como un engranaje más dentro de la alienación -que puede literalmente destruir al pueblo- en el de Solás la revolución ha permitido que el guajiro disfrute del fruto de su labor y, por lo tanto, esta es concebida como un paso en su liberación, en una lógica afín a los objetivos del régimen.

Pese a las relaciones que entreteje el filme con el contexto en el que fue producido, Humberto Solás, en una entrevista concedida a la revista Cine Cubano, en 1971, afirmó que los filmes dedicados a los "Cien años de lucha" surgieron "espontáneamente" de parte de los cineastas, lo que

hace patente que el cine cubano no es un aspecto de nuestra cultura que se halle marginado de las profundas inquietudes de nuestra vida cultural revolucionaria. [...] Es decir que los filmes que se han dedicado a los 'Cien años de lucha' no han sido el resultado de decisiones tomadas fríamente en un despacho $[\ldots]^{\prime 20}$.

Es interesante destacar cómo el testimonio de Solás naturaliza la relación entre cineastas y política cultural, al punto retratarla como una concordia "espontánea", radicada en el carácter fundamentalmente revolucionario de los primeros.

\section{La primera carga al machete}

De los cuatro largometrajes producidos por el ICAIC durante el ciclo de los "Cien años de lucha", La primera carga al machete es el único

20 CINE CUBANO. Cine cubano entrevista a los realizadores cuya obra reciente se integra en el ciclo dedicado a los Cien años de lucha por la liberación. Cine Cubano, La Habana, n. 68, p. 38, 1971. 
que está ambientado en la Guerra de los diez años, en cuyo centenario se había hecho pública la nueva interpretación oficial de la historia cubana. El filme de Manuel Octavio Gómez no aborda el conflicto en su totalidad-que se saldó con la derrota de las fuerzas independentistas- sino que describe uno de sus primeros episodios: la toma de la ciudad de Bayamo por los rebeldes cubanos y la subsiguiente victoria de los mambises dirigidos por Máximo Gómez, sobre las tropas españolas que habían acudido para sofocar la insurrección. La escasez de armas hizo que los rebeldes se batieran con machetes contra el ejército colonial, el 4 de noviembre de 1868 (25 de octubre según el filme). No se trató de un episodio que resultase decisivo para el transcurso de la guerra; sin embargo, la utilización del tradicional cuchillo le confirió un potente simbolismo. La herramienta de trabajo, fuertemente asociada a la idiosincrasia del campesinado cubano, sirvió como sinécdoque de la nación que se alzaba contra el colonialismo.

A pesar de la creciente hostilidad hacia la experimentación estética -tachada, recordemos, de "snobismo" extranjerizante por Castro en su discurso de Demajagua ${ }^{21}$ - el filme aborda este episodio alejándose drásticamente de las convenciones que han caracterizado al cine de reconstrucción histórica. Sin embargo, el objetivo de Manuel Octavio Gómez no por ello deja de ser monumentalizante, se trata de abordar uno de los mitos fundacionales de la identidad nacional y hacer de él un discurso de propaganda política y cultural. Sin embargo, los medios utilizados van en dirección opuesta a los códigos del género histórico. La reconstrucción del tiempo pasado es llevada a cabo a través de técnicas documentales, como si un equipo de reporteros y cineastas hubiese podido captar los hechos históricos en el momento mismo en que se estaban desarrollando, teniendo acceso, además, a ambos bandos. Para ello, el realizador utiliza una serie de recursos formales procedentes del cine directo, en boga en los años 1960 -cámara al hombro de gran movilidad; seguimiento cercano y constante de las acciones de los personajes; interés por la entrevista y el testimonio oral; intervención del entrevistador.

A lo anterior se añaden, en algunas secuencias, locuciones en over que siguen el estilo de notas breves de un informativo radial o televisivo. Hay, también, otras donde un tercer narrador hace una descripción expositiva de las acciones que se ven en la banda de imagen -fundamentalmente 
preparaciones de combates-, con una típica función de anclaje, que guía la lectura del espectador ${ }^{22}$. Se trata de un recurso utilizado en las primeras ediciones del Noticiero ICAIC Latinoamericano. Por último, como disgresión dentro del filme, se inserta un cortometraje documental "didáctico" sobre los usos del machete y su relación con la cultura cubana ${ }^{23}$.

Junto con ello, el alto contraste de las imágenes en blanco y negro, a cargo del director de fotografía Jorge Herrera, recuerda los primeros años del cine, en particular los filmes sobre la Guerra de Cuba rodados en 1898 y 1899 por equipos de la Edison Manufacturing Company, la American Mutoscope \& Biograph Company y de la productora Vitagraph ${ }^{24}$. La sobreexposición de la cámara también evoca las fotografías de época de los mambíes. Como se ha mencionado, Herrera ya había trabajado la sobreexposición como un elemento expresivo en el primer capítulo Lucía; sin embargo, el trabajo desempeñado aquí retoma y supera la crudeza visual de aquel segmento.

Un primer análisis llevaría a concluir que estos tres procedimientos buscan crear en el público la sensación de que asiste a un documento histórico registrado en el momento de los hechos y no a una recreación ficcional del pasado. Se tratarían, con ello, de inducir al público a realizar una "lectura documentalizante", atribuyendo las imágenes a "un enunciador real cuestionable en términos de verdad, un enunciador documentalizante"25. Desde el punto de vista de los acontecimientos históricos narrados, La primera carga al machete sí pretende que el espectador haga ese tipo de lectura, vale decir, que crea en el carácter verdadero de los hechos. Sin embargo, no se puede decir lo mismo de la puesta en escena. Difícilmente se podría considerar que el filme busque "confundir" al espectador, al punto de hacerlo

22 ODIN, Roger. De la fiction. Bruxelles: Éditions de Boeck Université, 2000. p. 136.

23 El "didáctico" fue un género documental muy desarrollado por el ICAIC para la educación y concienciación popular. En general estaba relacionado con el aprendizaje técnico o con la concientización en torno a alguna campaña pública (apoyo voluntario a las zafras de café y azúcar, por ejemplo).

24 A modo de ejemplo cabría mencionar Morro Castle, Havana Harbor (1898), Shooting captured insurgents (1898), Troops making military road in front of Santiago (1898), Wreck of the "Vizcaya" (1898), Wounded soldiers embarking in row boats (1898), Pack mules with ammunition on the Santiago Trail, Cuba (1898), Wreck of the battleship “Maine” (1898), Skirmish of Rough Riders (1899), General Lee's procession, Havana (1899) y Raising Old Glory over Morro Castle (1899). Los títulos citados provienen de la colección de la Biblioteca del Congreso de Estados Unidos, que ha puesto a libre disposición, en su sitio web, 68 filmes relacionados con la contienda. Muchos de ellos son recreaciones. Cf. LIBRARY OF CONGRESS. The Spanish-American War in Motion Pictures. Disponible en: <http://www.loc.gov/collection/spanish-american-war-in-motion-pictures/?q=\&sp=2>. Última visita: 27/09/2014.

25 ODIN. Op. cit., p. 133. 
creer en la veracidad o en el estatus no-ficcional de las imágenes que se le presentan, presuponiendo su carácter real (no así el de los hechos). Ello por la simple razón de que ni el cinematógrafo ni mucho menos las técnicas de cine directo habían sido creadas en 1868. El anacronismo que plantea abiertamente el filme es demasiado evidente como para resultar verosímil. Lo que se le propone al espectador parece, más bien, otro tipo de pacto: sin suspender la "lectura ficcionalizante" de la puesta en escena, "hacer como si" se tratara de un documental.

Es en ese juego, en ese "hacer como si", donde radica la apuesta central de Gómez. Ese "hacer como si" permite la actualización histórica. ¿Qué habría pasado si un grupo de documentalistas cubanos hubiesen podido registrar las primeras batallas de la independencia? Esa pregunta, que el filme contesta, permite recrear la Guerra de los diez años de una forma similar a como, en la misma época, el Noticiero del ICAIC abordaba los conflictos armados del Tercer Mundo. Al equiparar el relato del pasado al de las guerras del presente, ambos se vuelven formalmente (audiovisualmente) equivalentes. Lo anterior permite reforzar la tesis de los "Cien años de lucha" y los paralelos entre los héroes de la patria y los dirigentes del presente.

El filme está estructurado como un largo racconto, la acción comienza en un momento inmediatamente posterior a la victoria de los mambises sobre los españoles. Un trovador, encarnado por el cantautor Pablo Milanés, se pasea por un campo de batalla completamente devastado. A continuación, un grupo de soldados del ejército colonial dan su testimonio frente a la cámara acerca de la batalla. El entrevistador se encuentra siempre fuera de campo; sin embargo, podemos escuchar sus preguntas. Los soldados, muchos de los cuales están heridos, manifiestan su desconcierto frente a la violencia de la carga de los rebeldes. Afirman que la batalla duró horas y se ven visiblemente asombrados cuando el entrevistador les dice que solo ha durado quince minutos. El desconcierto de los soldados, su pánico al evocar los golpes de los machetes y las imágenes de devastación, están orientados a crear un clima de expectación y de curiosidad en el espectador. En la secuencia siguiente, unos burgueses de Bayamo, entre los que se encuentran militares y algunas mujeres, explican la situación militar. A partir de entonces, la película se dedica a narrar los hechos que llevaron a la batalla, cuyas consecuencias ya se han mostrado al público.

El recurso de las entrevistas, unido a la locución periodística de los narradores, confieren a los acontecimientos una impresión de actualidad y de 
urgencia. Así, en su primera intervención la voz over refuerza explícitamente el carácter "actual" de la acción en una alocución dirigida directamente al público: "Lo que acaban de ver y oír está sucediendo en el Departamento Oriental en estos precisos instantes. En los últimos meses de este dramático año de 1868 [...]" (la bastardilla es mía).

Mediante los testimonios de ciudadanos anónimos de Bayamo, Baire y de La Habana y las entrevistas a soldados y dirigentes de ambos bandos, se va construyendo progresivamente la acción. A la vez, esas entrevistas entregan información de contexto, lo que permite descubrir los motivos del alzamiento. Por último, de la boca de los propios mandos militares se obtienen sus motivaciones para participar de la guerra y sus análisis políticos e ideológicos del conflicto.

La cámara y la voz del entrevistador-me referiré a ambos como el "equipo de filmación"- constituyen entidades con atribuciones semejantes al resto de los personajes, están insertos en la acción y sus intervenciones tienen repercusiones sobre los acontecimientos: pueden provocar respuestas de los entrevistados o desencadenar discusiones entre estos. Asimismo, a pesar de que el "equipo de filmación" ofrece el punto de vista de los dos grupos en conflicto, ni el filme ni el propio "equipo" pretenden mantenerse neutrales. Tanto las declaraciones pacificadoras y a menudo diplomáticas del coronel Quiroz, a cargo de un destacamento español, como la verborrea autocomplaciente con la que el gobernador Francisco de Lersundi minimiza el alzamiento, son desmentidas por secuencias intercaladas donde queda de manifiesto la crueldad del ejército español que no duda en violar a mujeres, emponzoñar los pozos arrojándoles cadáveres o utilizar a la población como escudo humano. En este sentido, hay que destacar que a lo largo de $L a$ primera carga al machete la crueldad es patrimonio exclusivo del ejército colonial. La violencia rebelde es igualmente retratada, pero la puesta en escena y la musicalización de carácter épico la legitiman como una lucha por la autodeterminación nacional, como una forma, en definitiva, de liberación.

A lo largo de todo el filme se proponen paralelos entre el inicio de la Guerra de los diez años y la revolución cubana. Algunos de los recursos utilizados para ello evocan las similitudes en forma indirecta, otros lo hacen abiertamente. La revolución cubana es un elemento objetivamente ausente de la imagen, pero que domina todo el filme. La causa independentista es constantemente evocada como una "revolución" y los mambises como 
"revolucionarios". Durante la preparación de la emboscada que conducirá a la derrota española en Baire, los líderes independentistas Donato Mármol y Máximo Gómez dividen sus tropas y se comunican entre ellos con prismáticos. El gesto con el que Mármol le anuncia a Gómez que ha hecho contacto visual con él es muy significativo: un puño cerrado con el brazo en alto. En Bayamo una ciudadana anónima expresa su emotivo compromiso con la causa independentista con palabras de orgullo aplicables perfectamente al contexto de 1969. El fin didáctico y propagandístico de sus afirmaciones resulta bastante evidente: "Para mí, igual que para todos los cubanos, debe ser así algo muy emocionante y de verdad apasionante, el estar en algo tan digno y tan puro como es la revolución". En el mismo segmento de entrevistas, otro ciudadano hace una afirmación que puede interpretarse a la luz de los llamados a la unidad y sacrifico colectivo de la "Ofensiva revolucionaria": "Tenemos muy pocas armas. Solamente nos dará el triunfo, claro, la disciplina, la organización, los jefes que surgen en la lucha".

Los recursos utilizados para conferirle actualidad a los hechos históricos podrían contribuir a desmitificarlos, al hacer de ellos un relato similar al de cualquier otra guerra de mediados del siglo XX. Sin embargo, la música épica a cargo de Leo Brouwer, la figura del trovador -a la que me referiré más adelante- $y$ la fotografía de alto contraste de Herrera crean una atmósfera expresionista que reinserta las acciones armadas dentro del mito fundador de la nación. La sobreexposición de la fotografía se acrecienta ostensiblemente durante la batalla final, erradicando las tonalidades grises y haciendo de la contienda una amalgama de cuerpos de un blanco brillante - los mambises- enfrentados a otros de profunda oscuridad -los españoles. La cámara se desplaza entre ellos, como un combatiente más, acrecentando la confusión hasta llegar, como advierte Santiago Juan Navarro, momentos de semiabstracción visual ${ }^{26}$.

La batalla del 25 de octubre de 1868 viene precedida por una serie de secuencias en las que se hace una semblanza de Máximo Gómez, que mitifica al héroe nacional. El segmento comienza con el intertítulo "Anatomía de un Jefe", y está compuesto fundamentalmente por entrevistas a un oficial y a sus soldados. Estos explican, con mayor o menor precisión,

26 JUAN-NAVARRO, Santiago. Op. cit. La primera carga al machete (Manuel Octavio Gómez, 1969). Cine, mito y revolución. En: AMIOT, Julie; BERTHIER, Nancy (Dir.). Cuba: cinéma et révolution. Lyon: Le Grimh, 2006. p. 112. 
quién es Gómez y cómo llegó al ejército, mientras se preparan, en el campamento, para la batalla del día siguiente. A diferencia de los otros líderes militares, Máximo Gómez no es entrevistado en el filme y tampoco se oye su voz. Lo anterior, junto a las descripciones que hacen los hombres acerca de él, lo envuelven en cierta aura de misterio: algunos no están seguros de cómo se llama, otros no tienen muy claro cuál es su origen, uno compara su fisonomía con la de un gavilán. Solo el oficial parece conocerlo mejor.

Las descripciones del líder se alternan, tres veces, con imágenes de un caballo blanco que relincha al galope (el relinchido está pos-sincronizado y ralentizado). Cuando uno de los soldados dice que Gómez seleccionó a un grupo de hombres para formar su vanguardia, aparece en la pantalla un grupo de caballos al galope. Al igual que el caballo blanco todos van desensillados. La metáfora equina pone de manifiesto tanto el vigor indómito, como la libertad del líder y de su grupo.

Solo al final de este conjunto de secuencias aparece Gómez, a lo lejos, en plano general, y con el fondo sobreexpuesto a tal punto que la luz impide que se vean detalles de su fisonomía. El líder, que va a caballo, se pierde en la luz del fondo de la imagen. Una música de guitarra acompaña su aparición. La voz del trovador pone de manifiesto el encuentro del héroe con su destino: "A matar o a que lo maten, así marcha este soldado de la vida. Por arma lleva un machete, por tiempo la despedida".

La semblanza de Máximo Gómez, propone implícitamente, algunos paralelos con Ernesto Guevara. Tanto los soldados como el entrevistador insisten acerca del hecho de que Gómez no sea cubano, a algunos eso parece importarles, pero a la mayoría no. A su vez, el soldado que describe a Gómez como un gavilán hace aseveraciones que bien podrían aplicarse a Che Guevara, en 1959: "El tiene unos treinta años, más o menos alto, pelo negro. Tiene ojos de gavilán y cara de gavilán y monta tieso a caballo". Por último, los versos de Milanés parecen adaptarse mejor al Che que a Gómez: la referencia al momento de la despedida no tiene lógica en el caso del segundo, pues se involucró activamente en todo el proceso de independencia y fue uno de los líderes militares de la guerra de 1895. En cambio, sí podrían referirse a la salida de Guevara de Cuba, en 1965, con el objetivo de difundir la revolución tercermundista en el Congo y en Bolivia ("a matar o a que lo maten", como dice Milanés). Según Manuel Octavio Gómez, el paralelo con el Che no fue intencional, solo se "hizo patente" 
durante la elaboración del guión ${ }^{27}$. Sin querer tomar las declaraciones al pie de la letra, resulta interesante ver cómo en ellas las similitudes entre ambas figuras quedan naturalizadas, como si fueran de suyo, como si se trataran de datos objetivos de la realidad, que el cineasta solo tiene que recolectar, con independencia de su interpretación subjetiva.

Conviene, por último, detenerse en el personaje del trovador. Al igual que los narradores y el "equipo de filmación", tiene una función deíctica; sin embargo, en lugar de ofrecer un relato del conflicto como si este estuviera pasando, el lirismo con el que lo evoca lo convierte en leyenda, en mito intemporal. El cantautor se pasea por el escenario de la batalla, pero parece situarse fuera del tiempo y conocer las consecuencias de esa contienda y sus paralelos con la revolución. Los narradores y el "equipo de filmación" permiten establecer paralelos entre 1868 y 1968 abordando el pasado como un tema contingente y actual. El trovador, al contrario, lo hace poniendo de relieve el carácter mítico de la independencia y de la revolución. El filme se cierra con sus palabras, estableciendo la unidad atemporal de ambos contextos: "Cuando vagábamos solitarios en el tiempo sin presente, hubo que rescatar los siglos de la vida. Entonces hubo que pelear al filo del machete, entonces hubo que matar al filo del machete, mil batallas ganar al filo del machete, que estamos dando hoy".

\section{Conclusión}

Los dos filmes analizados aquí satisfacen las demandas del ciclo de los "Cien años de lucha". Sin embargo, lo hacen de forma diferente, tanto en lo que se refiere a su concepción del tiempo, como en su forma de posicionarse respecto de la tradición fílmica. Lucía da cuenta de los "Cien años de lucha" haciendo énfasis en su progresión teleológica. Se trata de un camino hacia la emancipación tanto femenina como nacional en el que cada una de las tres Lucía representa un momento evolutivo diferente. Por el contrario, La primera carga al machete actualiza el pasado al ponerlo en escena como si se tratara de un documental sobre un conflicto actual. A 
la vez, realiza constantes paralelos implícitos entre los eventos del pasado y los del presente. Es así como el eco del pasado resuena en el ahora y viceversa. En lo que respecta al posicionamiento de los filmes respecto de la historia del séptimo arte, Lucía establece un diálogo con uno de los filmes fundacionales del modelo narrativo hollywoodense, que es revisitado y adaptado para representar la historia cubana. Por el contrario, La primera carga al machete se embarca en una experimentación formal que explora los límites entre ficción y documental, actualizando con ello el tiempo pasado.

En 1971, el número 68 de Cine Cubano dedicó un extenso dossier -ocupa exactamente la mitad de la revista- al ciclo de los "Cien años de lucha". En él se llevó a cabo un recuento del trabajo realizado por el ICAIC desde 1968, en materia de cine histórico, mediante un cuestionario hecho a los realizadores de esos filmes: José Massip, Julio García-Espinosa, Jorge Fraga, Bernabé Hernández, Enrique Pineda Barnet, Manuel Herrera Humberto Solás y Manuel Octavio Gómez (las dos últimas entrevistas ya han sido evocadas $)^{28}$. Llama la atención que casi no hay menciones a cuestiones cinematográficas en los cinco artículos que anteceden a las entrevistas. Los dos primeros textos, que abren la revista, inscriben el dossier dentro del discurso oficial y sirven para guiar la lectura del resto. Se trata de un pasaje de una carta de José Martí y de un fragmento del discurso de Fidel Castro en la Demajagua. Los siguientes tres artículos analizan la historia cubana desde mediados del siglo XIX hasta la revolución de 1959, repitiendo la argumentación teleológica propia de los "Cien años de lucha". Sin embargo, sus autores no son historiadores, sino que cineastas del ICAIC: Manuel Pérez, Jorge Fraga y Pastor Vega. El Instituto parecía querer dejar en claro que adhería al mandato de llevar a cabo investigaciones históricas. Como puede deducirse, hay un orden jerárquico en la distribución de los artículos dedicados a los "Cien años de lucha". Primero la palabra de los líderes; después el análisis histórico; por último, el cine se hace presente a través del testimonio de los directores. Cada una de las subsecciones parece servir para garantizar el carácter revolucionario de lo que viene a continuación.

28 Los cineastas respondieron a tres preguntas referidas a los "Cien años de lucha", las estrategias estéticas seguidas en los filmes y su potencial de comunicación con el público cubano y latinoamericano. El enunciado de la primera pregunta incluye un posicionamiento sobre la manera de abordar el pasado en el cine cubano: "Ver la historia en función del presente y no como una serie de hechos estratificados carentes de interconexión ha sido uno de los logros de los filmes dedicados a los "Cien Años de Lucha", CINE CUBANO. Op. cit., p. 25. 
En estos textos se percibe un afán por demostrar el irrestricto apego del ICAIC a la política cultural del régimen. Ello puede ser leído a la luz de la difícil coyuntura que atravesaba la isla. Entre el 23 y el 30 de abril de 1971 tuvo lugar el Primer Congreso Nacional de Educación y Cultura cuyas resoluciones significaron una restricción a la libertad creativa, que ya se encontraba en crisis desde fines de los años $1960^{29}$. Aquellos comportamientos que pudieran resultar perjudiciales para la unidad de la revolución o que se alejasen de la norma fueron censurados y perseguidos, particularmente, la homosexualidad, la religiosidad, las reivindicaciones de los colectivos afrocubanos y las costumbres "desviadas" de la juventud como la vestimenta y la música de influencia anglosajona ${ }^{30}$. En el campo cultural esto significó la persecución - el término utilizado fue el de "parametración"- de aquellos artistas sospechosos de tener un comportamiento no adecuado. La "parametración" supuso la pérdida de sus puestos de trabajo y, eventualmente, penas de trabajos forzados o de reclusión.

En el congreso se planteó que la cultura debía unificarse y tener por objetivo la educación popular a gran escala. El ICAIC fue abiertamente criticado por la exhibición de filmes extranjeros, de un "capitalismo decadente", al tiempo que se le exigió incrementar la producción de documentales y filmes de ficción históricos, con una orientación didáctica ${ }^{31}$. Aunque el Instituto no sufrió las consecuencias del Congreso con la misma intensidad que otras instituciones-la censura alcanzó grados mayores en la literatura y en el teatro- sí vio peligrar su autonomía. En la práctica, se advierte en los años 1970 un menor experimentalismo formal en las producciones y un aumento considerable del cine histórico. Esta opción por el cine histórico no significó un cambio temático profundo, pues este ya había alcanzado un papel protagónico a partir de 1968; sin embargo, al comparar los nuevos estrenos con La primera carga al machete y Lucía se percibe una menor inquietud por revolucionar las formas autónomas del cine mediante el cuestionamiento de los límites genéricos o la relectura de

29 Los años 1970 han sido descritos frecuentemente como un periodo gris para la cultura cubana, particularmente tras la noción de "Quinquenio Gris" acuñada por Ambrosio Fornet, para describir el periodo entre 1971 y 1975. Sin embargo, el origen de la rigidez en materia cultural puede rastrearse en el decenio anterior. Cf. FORNET, Ambrosio. Trente ans de cinéma dans la Révolution. En: PARANAGUÁ, Paulo Antonio (Dir.). Le cinéma cubain. Paris: Centre Pompidou, 1990. p. 91.

30 MISKULIN, Sílvia Cezar. Op. cit., p. 227-236.

31 DEL RÍO, Joel; DÍAZ, Marta. Los cien caminos del cine cubano. La Habana: Ediciones ICAIC, 2010. p. 37-38. 
la tradición. Las innovaciones de finales de los años 1960 se convirtieron en un rasgo estilístico cada vez más socorrido. La historia siguió siendo objeto de una mitificación propagandística, pero la repetición de fórmulas expresivas ya probadas hizo que la representación del pasado se petrificara progresivamente, petrificando también el tiempo histórico cuya memoria pretendía rescatar.

Recebido em: 25/03/2014. Aprovado em: 15/06/2014. 